\title{
EDITORIAL
}

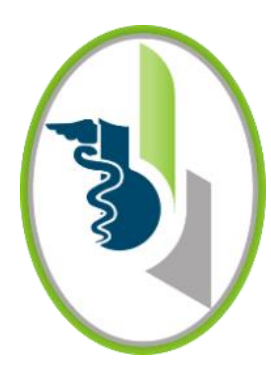

ACCESO 2 ABIERTO

Copyright: (C) 2020. Diaz, A., Simancas, V., Álvarez, A. Este es un artículo de acceso abierto, distribuido bajo los términos de la licencia https://creativecommons.org/licenses/by-nc-

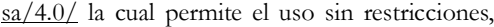
distribución y reproducción en cualquier medio, siempre y cuando el original, el autor y la fuente sean acreditados.

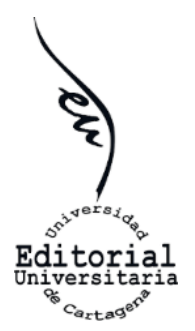

\section{La estrategia de los semilleros de investigación dentro de las universidades}

Es de aparente común conocimiento que la formación de nuevo capital humano en investigación, juega un papel poco examinado en el reconocimiento de los estudiantes como científicos en formación por parte de los profesores (1). En muchas oportunidades las actividades desarrolladas dentro de los grupos de investigación no alcanzan a ser reconocidas de manera satisfactoria por los docentes en alta manera. Con frecuencia, los docentes no son flexibles en diversas circunstancias a la opción de dar un apoyo más decidido a ese joven semillerista en un claro intento de freno de sus ideales de investigación dentro de un grupo de investigaciones, sea por desconocimiento o por una actitud de egoísmo.

Se establece que el semillero de investigación es un espacio de desmitificación de la ciencia, para volverla algo cotidiano, para convertir la ciencia en algo de manejo del día a día, que permita el cultivo de las competencias básicas auto dirigidas de la actividad investigativa de una forma autónoma, pero con una orientación adecuada y permanente (2). Al interior de las universidades, particularmente en los grupos de investigaciones, se apuesta a este tipo de herramientas de desarrollo cognitivo no a corto plazo. Por lo contrario, es una propuesta de formación a largo plazo donde se puede tener una diversidad de talentos humanos que permitirán obtener un tejido humano de reemplazo de los docentes y de los investigadores actuales.

Estos estudiantes investigadores deben tener dentro de su estructura de pensamiento y de cognición, la capacidad de ser aspirantes capacitados, con compromiso, motivados para el desarrollo de sus tareas y en especial con una alta dosis de tolerancia a la frustración para poder resistir los embates de las negaciones a aceptar sus trabajos en revistas, soportar el rechazo de un concurso para una pasantía o una participación en eventos. No es una tarea sencilla la que toca desarrollar en ambos sentidos, tanto en el semillerista como en el tutor, no es un trabajo breve porque se les debe inculcar una estructura de pensamiento de diferenciación con sus pares compañeros de carrera o de semestre. Se debe construir una filosofía de duda metódica que apunte a la formación de un pensamiento crítico que le facilite el no aceptar de forma pasiva las ideas o conceptos con los que se forma diariamente.

Ser parte de un semillero de investigación, exige una dosis alta de manejo interpersonal, de saber entender al otro y de poder desarrollar procesos constructivos de conocimiento aun dentro del campo de la no concordancia de filosofías y de pensamientos. Muchas veces son los docentes y los mismos tutores quienes se encargan de cortar las alas, de frustrar sueños de desarrollo de competencias investigativas de esos estudiantes de semilleros. Esta situación se da por no conocer a fondo la filosofía de un semillero de investigación, creyendo falsamente que es un lugar de obtención de mano de obra barata o gratis y no se alcanza a percibir por parte del tutor, el deseo imperioso de aprender por parte de 
esos estudiantes, quienes muchas veces lo hacen por imitación de su docente guía.

En diversas oportunidades lo que se presenta es la negativa sistemática y continua de ese semillero en aceptar una palabra oportuna, un llamado de atención, una frenada adecuada y a tiempo para no caer en un error de construcción de pensamiento o de estilo de trabajo. De allí que ese mensaje puede ser muy benéfico para retomar una ruta, un camino o un estilo de construcción de investigación (3). Claro que no dejan de existir estudiantes que manejan el concepto de la auto suficiencia o el concepto de la zona de confort, los cuales pueden generar mucho daño en su proceso de formación como investigador en una de las etapas de su crecimiento dentro de la cultura y proceso de investigación.

La invitación se extiende a los estudiantes y en especial a los docentes para que acompañen de forma permanente y categórica esta filosofía de trabajo en las universidades. Que no sea una lucha exclusivamente del director del grupo, en cultivar esos talentos, en reclutarlos en su propio beneficio personal, sino que se piense de manera colectiva en que es una apuesta de ganar, ganar para todos y cada uno. No es solamente en beneficio de un grupo de investigación o de un tutor en especial. Es una filosofía de trabajo que se puede plasmar de una forma transversal en todo el recorrido académico de ese estudiante. Estudiante que, al convertirse en un investigador, tendrá más y mejores oportunidades de crecimiento personal y al mismo tiempo, puede en su recorrido universitario dejar plasmados varios productos académicos que se puedan evidenciar de manera grata y de alto reconocimiento para las instituciones educativas.

\author{
Antonio Díaz-Caballero (i) \\ Odontólogo, M.Sc., PhD. \\ Profesor \\ Facultad de Odontología \\ Grupo Gitouc \\ Universidad de Cartagena \\ Víctor Simancas-Escorcia \\ Odontólogo, M.Sc. \\ $\mathrm{PhD}$ (c), Université de Paris \\ Grupo Gitouc \\ Andrea Álvarez-Ojeda \\ Universidad de Cartagena
}

Pregrado, Facultad de Odontología

Semillero de investigación Grupo Gitouc 


\section{REFERENCIAS BIBLIOGRÁFICAS}

1. Thompson JJ, Jensen-Ryan D. Becoming a «Science Person»: Faculty Recognition and the Development of Cultural Capital in the Context of Undergraduate Biology Research. CBE Life Sci Educ. 2018;17(4):ar62.

2. Ward JR, Clarke HD, Horton JL. Effects of a research-infused botanical curriculum on undergraduates' content knowledge, STEM competencies, and attitudes toward plant sciences. CBE Life Sci Educ. 2014;13(3):387-96.

3. Olimpo JT, Fisher GR, DeChenne-Peters SE. Development and Evaluation of the Tigriopus Course-Based Undergraduate Research Experience: Impacts on Students' Content Knowledge, Attitudes, and Motivation in a Majors Introductory Biology Course. CBE Life Sci Educ. 2016;15(4). 